\title{
(1) \\ Low Severity Coal Liquefaction Promoted by Cyclic Olefins
}

\author{
Grant No. DE-FG22-91PC-91281 \\ Quarterly Report \\ July to September 1993
}

\begin{abstract}
DISCLAIMER
This report was prepared as an account of work sponsored by an agency of the United States Government. Neither the United States Government nor any agency thereof, nor any of their employees, makes any warranty, express or implied, or assumes any legal liability or responsibility for the accuracy, completeness, or usefulness of any information, apparatus, product, or process disclosed, or represents that its use would not infringe privately ewned rights. Reference herein to any specific commercial product, process, or service by trade name, trademark, manufacturer, or otherwise does not necessarily constitute or imply its endorsement, recommendation, or favoring by the United States Government or any agency thereof. The views and opinions of authors expressed herein do not necessarily state or reflect those of the United States Government or any agency thereof.
\end{abstract}

\section{Christine W. Curtis}

Chemical Engineering Department

Auburn University, AL 36849 


\section{Acknowledgments}

The research of An Ping Huang and Thomas Beasley is sincerely appreciated. The word processing and editorial skills of Patricia Sandlin made this document possible. The technical support of Frank Bowers, Mike Hornsby, and Joe Aderholdt are appreciated by all of us. 


\section{Table of Contents}

Part I. Low Severity Liquefaction Studies Using Hexahydroanthracene . . . . . . . 1

Introduction . . . . . . . . . . . . . . . . . . . . . . . . 1

Experimental . . . . . . . . . . . . . . . . 2

Results \& Discussion . . . . . . . . . . . . . . . . . . . . . . . . 4

Summary . . . . . . . . . . . . . . . . . . . . . . . . 8

References . . . . . . . . . . . . . . . . . . . 8

Part II. A Study of the Effects of Mild Acidic Pretreatment

to Enhance Low-Severity Coal Liquefaction Promoted by Cyclic Olefins . . 11

Introduction . . . . . . . . . . . . . . . . . . . 12

Experimental . . . . . . . . . . . . . . . . . . 13

Results and Discussion . . . . . . . . . . . . . . . . . . . . . 14

Summary . . . . . . . . . . . . . . . . . . 14

References . . . . . . . . . . . . . . . . . 15

Appendix A . . . . . . . . . . . . . . . . . . . . . . . 16

Appendix B . . . . . . . . . . . . . . . . . . . . . 18

Appendix C . . . . . . . . . . . . . . . . . . . . . 20 


\title{
Low Severity Liquefaction Promoted by Cyclic Olefins
}

\author{
PART I \\ LOW SEVERITY LIQUEFACTION STUDIES USING \\ HEXAHYDROANTHRACENE
}

\section{Introduction}

Low-severity coal liquefaction allows for the solubilization of coal with reduced gas make. The idea being tested in this research is whether selective bond rupture occurs during liquefaction at low temperatures that can be satisfied by hydrogen donation from highly active hydrogen donor compounds. Promotion of coal solubilization through hydrogen transfer using highly active and effective hydrogen donors is the objective of this study.

The highly effective hydrogen donors being tested are cyclic olefins. Representative cyclic olefins are isotetralin (ISO), which is $1,4,5,8$-tetrahydronaphthalene, and 1,4,5,8,9,10hexahydroanthracene (HHA). These compounds have been shown to highly effective donors (Bedell and Curtis, 1991) which release their hydrogen at fairly low temperatures, in the 200 to $300{ }^{\circ} \mathrm{C}$ range. ISO has been shown to be much more effective than its hydroaromatic analogue tetralin (TET) in releasing hydrogen at low temperatures and transferring that hydrogen to an acceptor molecule or to coal (Bedell and Curtis, 1991). Likewise, at $380^{\circ} \mathrm{C}$, the ability of HHA to release hydrogen in both $\mathrm{N}_{2}$ and $\mathrm{H}_{2}$ atmospheres was greater than a comparative hydroaromatic compound, dihydroanthracene (DHA). However, when an acceptor molecule or coal was present, DHA was as or more active than HHA in transferring hydrogen (Bedell et al., 1993). In another study, at equivalent reaction conditions and in the presence of anthracene (ANT) as a hydrogen acceptor, ISO released more than 200 times as much hydrogen as TET and HHA released 18 to 25 times as much hydrogen as DHA (Wang, 1992). 
The objective of the research performed this quarter was to evaluate the effect of coal pretreatment on the conversion of Illinois No. 6 bituminous coal and Wyodak subbituminous coal. The pretreatment that was effected used $\mathrm{HCl}$ and methanol in a procedure described by Beasley in previous quarterly reports. Three different catalytic reactions were compared for each coal: (1) catalytic reaction with untreated coal and Mo naphthenate plus sulfur but without HHA as donor present; (2) catalytic reaction with untreated coal and Mo naphthenate with HHA present; and (3) catalytic reaction with acid pretreated coal and Mo naphthenate with HHA present. Hence, the effect of the presence of the donor and the effect of coal pretreatment on the reactivity were evaluated.

\section{Experimental}

A parametric evaluation of Illinois No. 6 coal reacted in the presence of hexahydroanthracene ( $97 \%$ purity from Aldrich) using hexadecane ( $99 \%$ purity from Aldrich) as solvent was performed. The reactions were performed thermally and catalytically using molybdenum naphthenate and excess sulfur. Molybdenum naphthenate, obtained from Shepherd Chemical Company, contained 6\% Mo and was used as received.

Low-severity liquefaction reaction conditions were employed. The reactions were performed in $\sim 50 \mathrm{~cm}^{3}$ stainless steel tubular reactors that were well agitated. The reactor was charged with $2 \mathrm{~g}$ of coal and $4 \mathrm{~g}$ of solvent. The solvent was composed of hexadecane and hexahydroanthracene. When hexahydroanthracene was present at $0.5 \mathrm{wt} \%$ donable hydrogen, $0.61 \mathrm{~g}$ was introduced and, at $1.0 \mathrm{wt} \%$ donable hydrogen, $1.22 \mathrm{~g}$ was introduced. In both cases, hexadecane composed the remainder of the solvent. The base line conditions were 350 ${ }^{\circ} \mathrm{C}, 500$ psig $\mathrm{H}_{2}$ introduced at ambient temperature, and $0.5 \mathrm{wt} \%$ donable hydrogen from 
hexahydroanthracene. Molybdenum naphthenate was introduced at $500 \mathrm{ppm}$ with a sulfur level of $3: 1 \mathrm{~S}$ to Mo stoichiometric ratio when Mo was introduced at $500 \mathrm{ppm}$, presuming that finely divided $\mathrm{MoS}_{2}$ would form during the reaction (Kim et al., 1989; Huffman and Huggins, 1993). Different combinations of reaction parameters were used which included reaction times of 60 min, catalyst loading of $1000 \mathrm{ppm}$ of active metal, hydrogen pressures of $1000 \mathrm{ppm}$ and donable hydrogen concentrations of $1.0 \mathrm{wt} \%$. The different combinations of parameters used in reactions performed this quarter are presented in Table 1. In each reaction set, at least three parameters were changed from the base line conditions.

After the reactions were performed at the chosen conditions, the reaction products were analyzed. The amount of coal conversion obtained was determined by evaluating the amount of coal converted to tetrahydrofuran soluble materials. The products from the liquefied coal were analyzed in terms of gas, oil (hexane soluble material), asphaltenes (toluene soluble material, hexane insoluble material), preasphaltenes (tetrahydrofuran soluble material, toluene insoluble material) and insoluble organic matter (THF insoluble and ash free). The data presented in the report are given in terms of the total product distribution in grams, total product distribution normalized in weight percent, and the solvent-free distribution normalized in weight percent. The distribution of the reaction system prior to reaction is also given in weight percent.

The product analysis for hexahydroanthracene and its reaction products was conducted using a Varian 3700 gas chromatograph equipped with a J\&W DB-5 column, septumless injector and a flame ionization detector. The hydrogenated products were qualitatively identified by spiking with authentic compounds and by analyzing with GC mass spectrometry using a VG 70 EHF-GC mass spectrometer. Quantitative analysis of the reaction products was achieved using the internal standard method with p-xylene as the internal standard. 
The following term, percent hydrogenation (\% HYD) of hexahydroanthracene, is defined to assist in comparing the results from a number of reactions. Percent hydrogenation is defined as the number of moles of hydrogen required to produce the liquid products as a percentage of the number of moles of hydrogen required to achieve the most hydrogenated product, in this case, perhydroanthracene.

Mild Acid Pretreatment of Coal. Mild acid pretreatment of coal was performed by pretreating $5 \mathrm{~g}$ of coal with $40 \mathrm{ml}$ of methanol and $0.4 \mathrm{ml}$ of concentrated hydrochloric acid solution. The solution with coal present was then shaken vigorously for $3 \mathrm{hr}$ at room temperature. The solution is then centrifuged for 10 to $15 \mathrm{~min}$. The solution was filtered using a Coors porcelain filter and Whatman 5 Qualitative filter paper. The residual coal in the centrifuge bottle and the filter cake were washed with methanol. The coal was then removed from the filter paper, placed in a Petri dish, and dried in a vacuum oven at room temperature. After drying, the coal was used in liquefaction reactions.

\section{Results and Discussion}

The research performed this quarter focused upon evaluating the effect of mild acid pretreatment on the efficacy of low severity coal liquefaction using cyclic olefins as donors. The cyclic olefin used in this particular set of experiments was 1,4,5,8,9,10-hexahydroanthracene (HHA). These reactions evaluated the effect of combining coal pretreatment with hydrogen donation from cyclic olefins on the efficacy of low-severity coal liquefaction, particularly in terms of coal conversion and hexane soluble yields.

The data presented in the tables are given in terms of (1) total product distribution in grams; (2) total product distribution normalized in weight percent; (3) solvent-free product 
distribution normalized il. ws.ght percent; and (4) original distribution prior to reaction in weight percent. The reaction conditions for each reaction set are given in each table.

Two different coals were used for acid pretreatment: Illinois No. 6 bituminous coal and Wyodak subbituminous coal. The results for reactions without a hydrogen donor present with untreated coal, with hydrogen donor present with untreated coal and with hydrogen donor present with pretreated coal are given for each coal in Tables 1 and 2 , respectively. The hydrogen donor used in these reactions was HHA which was introduced at a level of 1 wt\% donable hydrogen. The hydrogen pressure in these reactions was 500 psi introduced at ambient temperature. A reaction time of 60 min was used with a catalyst loading of $1000 \mathrm{ppm}$ Mo as Mo naphthenate which was reacted in the presence of sulfur.

The coal conversions of Illinois No. 6 coal presented in Table 1 show the strong effect of the hydrogen donor on the reaction system. Coal conversion increased from $31.1 \%$ with untreated coal without HHA to $62.7 \%$ with HHA. The effect of pretreatment with HHA present was small but did provide an additional increase in coal conversion in which $67 \%$ coal conversion was achieved. The product distribution in terms of the hexane soluble oil increased with the addition of HHA. The oil increased from $9.4 \%$ without HHA to $42.5 \%$ with HHA on a solvent-free basis. By contrast, the product distribution suffered with the acid pretreatment even with HHA present. The amount of oil produced on a solvent-free basis decreased to 14.7\%. The amount of preasphaltenes increased substantially from $24 \%$ with the untreated coal and HHA to $56.8 \%$ with pretreated coal and HHA.

Acid pretreatment is known to be more effective with lower rank lignite and subbituminous coals than with higher rank bituminous coals. Therefore, Wyodak coal was pretreated and liquefied for comparison. The results of these reactions are presented in Table 2. The liquefaction of untreated Wyodak coal without HHA yielded a coal conversion of 
$23.5 \%$. An oil yield of $37 \%$ was achieved on a solvent-free basis. The liquefaction of untreated Wyodak with HHA resulted in subtantially more coal conversion yielding $39.9 \%$ and an oil yield of $50.2 \%$ on a solvent-free basis. The lower rank Wyodak coal responded to the presence of the hydrogen donor in the same manner as Illinois No. 6 coal did, although Wyodak was not as reactive as Illinois No. 6 and did not yield as high a coal conversion. The hydrogen donor enhanced both coal conversion and oil yield.

The effect of pretreating Wyodak coal with mild acid treatment was observed in the amount of coal conversion with HHA. The coal conversion of the pretreated coal increased to $48.6 \%$ from $39.9 \%$ with the untreated coal. The amount of coal conversion increased more with pretreatment using the lower rank Wyodak coal than with the higher rank Illinois No. 6 coal. The oil fraction with the pretreated Wyodak on a solvent-free basis was $46.2 \%$ which was a small decrease from the untreated Wyodak coal which gave $50.2 \%$ oil. The higher rank Illinois No. 6 coal showed a much higher decrease in the oil fraction.

The product distributions obtained from HHA from the reactions using untreated and pretreated coals are presented in Table 3 . The product distributions obtained with untreated and pretreated Illinois No. 6 showed some differences. More DHA was produced with untreated coal while more OHA was obtained with pretreated coal. The untreated coal resulted in more dehydrogenation of the HHA system than did pretreated coal on the HHA system. The product distributions obtained from HHA with Wyodak coal, by contrast, were nearly identical for both the untreated and pretreated coals.

\section{Summary}

Pretreatment of either Illinois No. 6 bituminous coal or Wyodak subbituminous coal resulted in improved coal conversion in the presence of hexahydroanthracene, a cyclic olefin. 
A larger improvement was obtained with pretreated Wyodak than with pretreated Illinois No. 6 coal.

\section{References}

Bedell, M.W. and Curtis, C.W. Energy and Fuels, 5, 469, 1991.

Bedell, M.W., Curtis, C. W., and Hool, J.W. Energy and Fuels, 7, 200, 1993.

Curtis, C.W. Quarterly Reports, "Low Severity Coal Liquefaction Promoted by Cyclic Olefins," July-September, 1992; October-December 1992.

Huffman, G.P.; Ganguly, B.; Zhao, J.; Rao, K.R.P.; Shah, N.; Feng, Z; Huggins, F.E.; Taghiei, M.M.; Lu, F.; Wendu, I.; Pradhar, V.R.; Treiney, J.W.; Seehra, M.S.; Ibrahim, M.M.; Shabtai, J.; and Eyring, E.M. Energy and Fuels, 7, 285-296, 1993.

Kim, H.; Curtis, C.W.; Cronauer, D.C.; Sajkowski, D.J. Amer. Chem. Soc. Fuel Chem. Div. Prepr., 34(4):1431-1438, 1989.

Personal communication, Dr. G. P. Huffman and Dr. E. E. Huggins, 1993. 
Table 1. Effect of Coal Pretreatment on te Product Distributions from lllinois No. 6 Coal

\begin{tabular}{|c|c|c|c|}
\hline $\begin{array}{c}\text { Product } \\
\text { Distribution } \\
\text { (weight in grams) }\end{array}$ & $\begin{array}{c}\text { Untreated } \\
\text { Illinois No. } 6 \text { Coal } \\
\text { Without HHA }\end{array}$ & $\begin{array}{c}\text { Untreated } \\
\text { Illinois No. } 6 \text { Coal } \\
\text { With HHA }\end{array}$ & $\begin{array}{c}\text { Pretreated } \\
\text { Illinois No. } 6 \text { Coal } \\
\text { With HHA }\end{array}$ \\
\hline \multicolumn{4}{|c|}{ Total Product Distribution, g } \\
\hline $\begin{array}{l}\text { Gas } \\
\text { Oil } \\
\text { Aspaltenes } \\
\text { Preasphaltenes } \\
\text { IOM }\end{array}$ & $\begin{array}{l}0.085 \pm 0.075 \\
3.767 \pm 0.025 \\
0.113 \pm 0.020 \\
0.458 \pm 0.022 \\
1.072 \pm 0.022\end{array}$ & $\begin{array}{l}0.155 \pm 0.007 \\
3.538 \pm 0.039 \\
0.330 \pm 0.007 \\
0.759 \pm 0.053 \\
0.577 \pm 0.023\end{array}$ & $\begin{array}{l}0.145 \pm 0.007 \\
2.846 \pm 0.225 \\
0.243 \pm 0.032 \\
1.802 \pm 0.020 \\
0.516 \pm 0.027\end{array}$ \\
\hline Coal Conversion, $\%$ & $31.10 \pm 1.39$ & $62.91 \pm 1.50$ & $66.98 \pm 1.77$ \\
\hline Recovery, \% & $93.75 \pm 1.96$ & $91.63 \pm 1.22$ & $94.83 \pm 3.42$ \\
\hline \multicolumn{4}{|c|}{ Total Product Distribution Normalized, wt\% } \\
\hline $\begin{array}{l}\text { Gas } \\
\text { Oi } \\
\text { Asphaltenes } \\
\text { Preasphaltenes } \\
\text { IOM }\end{array}$ & $\begin{array}{r}1.45 \pm 1.32 \\
70.61 \pm 2.43 \\
1.92 \pm 0.35 \\
7.79 \pm 0.37 \\
18.23 \pm 0.39\end{array}$ & $\begin{array}{r}2.64 \pm 0.11 \\
69.02 \pm 0.39 \\
5.62 \pm 0.09 \\
12.91 \pm 0.97 \\
9.81 \pm 0.37\end{array}$ & $\begin{array}{r}2.47 \pm 0.11 \\
53.93 \pm 0.39 \\
4.13 \pm 0.54 \\
30.69 \pm 0.23 \\
8.78 \pm 0.48 \\
\end{array}$ \\
\hline \multicolumn{4}{|c|}{ Solvent-Free Product Distribution Normalized, wt\% } \\
\hline $\begin{array}{l}\text { Gas } \\
\text { Oil } \\
\text { Asphaltenes } \\
\text { Preasphaltenes } \\
\text { IOM }\end{array}$ & $\begin{array}{r}4.45 \pm 4.07 \\
9.43 \pm 7.40 \\
5.91 \pm 1.07 \\
24.60 \pm 1.12 \\
56.21 \pm 1.13\end{array}$ & $\begin{array}{r}4.90 \pm 0.24 \\
42.47 \pm 0.30 \\
10.42 \pm 0.25 \\
23.97 \pm 1.61 \\
18.24 \pm 0.82\end{array}$ & $\begin{array}{r}4.57 \pm 0.23 \\
14.71 \pm 0.97 \\
7.65 \pm 1.02 \\
56.81 \pm 0.59 \\
16.26 \pm 0.87 \\
\end{array}$ \\
\hline \multicolumn{4}{|c|}{ Original Distribution Normalized, wt\% } \\
\hline $\begin{array}{l}\text { Gas } \\
\text { Coal } \\
\text { HHA } \\
\text { Hexadecane } \\
\text { Catalyst }\end{array}$ & $\begin{array}{r}2.59 \pm 0.02 \\
32.46 \pm 0.03\end{array}$ & $\begin{array}{r}2.60 \pm 0.01 \\
32.23 \pm 0.24 \\
19.87 \pm 0.04 \\
44.36 \pm 0.20 \\
0.94 \pm 0.01\end{array}$ & $\begin{array}{r}2.60 \pm 0.00 \\
32.60 \pm 0.08 \\
19.92 \pm 0.07 \\
43.79 \pm 0.15 \\
1.10 \pm 0.00\end{array}$ \\
\hline
\end{tabular}

Reaction Conditions: Hydrogen Pressure 500 psi, reaction time $60 \mathrm{~min}, 2 \mathrm{~g}$ of Illinois No. 6 coal, $1.22 \mathrm{~g}$ of HHA when present, $1000 \mathrm{ppm}$ of Mo on a feed basis. 
Table 2. Effect of Coal Pretreatment on the Product Distributions from Wyodak Coal

\begin{tabular}{|c|c|c|c|}
\hline $\begin{array}{c}\text { Product } \\
\text { Distribution } \\
\text { (weight in grams) }\end{array}$ & $\begin{array}{l}\text { Untreated } \\
\text { Wyodak Coal } \\
\text { Witout HHA }\end{array}$ & $\begin{array}{c}\text { Untreated } \\
\text { Wyodak Coal } \\
\text { With HHA }\end{array}$ & $\begin{array}{c}\text { Pretreated } \\
\text { Wyodak Coal } \\
\text { With HHA }\end{array}$ \\
\hline \multicolumn{4}{|c|}{ Total Product Distribution, $\mathrm{g}$} \\
\hline $\begin{array}{l}\text { Gas } \\
\text { Oil } \\
\text { Aspaltenes } \\
\text { Preasphal'enes } \\
\text { IOM }\end{array}$ & $\begin{array}{l}0.155 \pm 0.007 \\
3.906 \pm 0.036 \\
0.056 \pm 0.005 \\
0.103 \pm 0.005 \\
1.003 \pm 0.053\end{array}$ & $\begin{array}{l}0.150 \pm 0.000 \\
3.627 \pm 0.016 \\
0.251 \pm 0.036 \\
0.417 \pm 0.003 \\
0.811 \pm 0.013\end{array}$ & $\begin{array}{l}0.145 \pm 0.007 \\
3.612 \pm 0.007 \\
0.282 \pm 0.058 \\
0.679 \pm 0.009 \\
0.653 \pm 0.036\end{array}$ \\
\hline Coal Conversion, $\%$ & $23.53 \pm 4.03$ & $39.91 \pm 0.66$ & $48.64 \pm 0.02$ \\
\hline Recovery, \% & $86.86 \pm 1.27$ & $88.28 \pm 1.35$ & $90.66 \pm 0.12$ \\
\hline \multicolumn{4}{|c|}{ Total Product Distribution Normalized, wt\% } \\
\hline $\begin{array}{l}\text { Gas } \\
\text { Oi } \\
\text { Asphaltenes } \\
\text { Preasphaltenes } \\
\text { IOM }\end{array}$ & $\begin{array}{r}2.57 \pm 0.11 \\
78.17 \pm 0.75 \\
0.93 \pm 0.08 \\
1.70 \pm 0.04 \\
16.63 \pm 0.91\end{array}$ & $\begin{array}{r}2.51 \pm 0.03 \\
72.72 \pm 0.58 \\
4.21 \pm 0.64 \\
6.98 \pm 0.01 \\
13.58 \pm 0.37\end{array}$ & $\begin{array}{r}2.43 \pm 0.07 \\
70.39 \pm 1.26 \\
4.74 \pm 0.88 \\
11.44 \pm 0.08 \\
11.00 \pm 0.39\end{array}$ \\
\hline \multicolumn{4}{|c|}{ Solvent-Free Product Distribution Normalized, wt\% } \\
\hline $\begin{array}{l}\text { Gas } \\
\text { Oil } \\
\text { Asphaltenes } \\
\text { Preasphaltenes } \\
\text { IOM }\end{array}$ & $\begin{array}{r}7.41 \pm 0.34 \\
37.02 \pm 2.05 \\
2.70 \pm 0.25 \\
4.90 \pm 0.11 \\
47.97 \pm 2.53\end{array}$ & $\begin{array}{r}4.58 \pm 0.06 \\
50.23 \pm 1.27 \\
7.69 \pm 1.20 \\
12.73 \pm 0.07 \\
24.77 \pm 0.05\end{array}$ & $\begin{array}{r}4.44 \pm 0.08 \\
46.16 \pm 1.76 \\
8.59 \pm 1.52 \\
20.81 \pm 0.35 \\
20.00 \pm 0.51\end{array}$ \\
\hline \multicolumn{4}{|c|}{ Original Distribution Normalized, wt\% } \\
\hline $\begin{array}{l}\text { Gas } \\
\text { Coal } \\
\text { HHA } \\
\text { Hexadecane } \\
\text { Catalyst }\end{array}$ & $\begin{array}{r}2.62 \pm 0.04 \\
32.42 \pm 0.05\end{array}$ & $\begin{array}{r}2.62 \pm 0.03 \\
33.68 \pm 0.59 \\
18.44 \pm 0.30 \\
44.16 \pm 0.26 \\
1.10 \pm 0.00\end{array}$ & $\begin{array}{r}2.64 \pm 0.06 \\
31.93 \pm 1.06 \\
20.27 \pm 0.44 \\
44.05 \pm 0.56 \\
1.11 \pm 0.01\end{array}$ \\
\hline
\end{tabular}

Reaction Conditions: Hydrogen Pressure 500 psi, reaction time $60 \mathrm{~min}, 2 \mathrm{~g}$ of Wyodak coal, $1.22 \mathrm{~g}$ of HHA when present, $1000 \mathrm{ppm}$ of Mo on a feed basis. 
Table 3. Product Distribution from Hexahydroanthracene from

Reactions Using Pretreated Coal.

\begin{tabular}{|c|c|c|c|c|c|c|c|c|}
\hline Cosl & Catalysts & Thme & \multirow{2}{*}{$\begin{array}{c}\text { Pressure } \\
\text { (psi) }\end{array}$} & & \multicolumn{4}{|c|}{ Product Distribution (wt\%) } \\
\cline { 5 - 9 } & & & ANT & DHA & HHA & OHA & HYD\% \\
\hline $\begin{array}{c}\text { Untreated } \\
\text { Illinois No. 6 }\end{array}$ & $\begin{array}{c}1000 \mathrm{ppm} \\
\text { MoNaph }\end{array}$ & 60 & 500 & $8.09 \pm 1.37$ & $37.84 \pm 1.96$ & $42.28 \pm 2.15$ & $11.79 \pm 0.52$ & -12.59 \\
\hline $\begin{array}{c}\text { Pretreated } \\
\text { Illinois No. 6 }\end{array}$ & $\begin{array}{c}1000 \mathrm{ppm} \\
\text { MoNaph }\end{array}$ & 60 & 500 & $7.15 \pm 2.91$ & $27.04 \pm 0.89$ & $46.10 \pm 1.04$ & $19.71 \pm 1.40$ & -7.97 \\
\hline $\begin{array}{c}\text { Untreated } \\
\text { Wyodak }\end{array}$ & $\begin{array}{c}1000 \mathrm{ppm} \\
\text { MoNaph }\end{array}$ & 60 & 500 & $16.68 \pm 3.58$ & $21.31 \pm 2.45$ & $49.59 \pm 1.35$ & $12 ., 42 \pm 1.74$ & -11.46 \\
\hline $\begin{array}{c}\text { Pretreated } \\
\text { Wyodak }\end{array}$ & $\begin{array}{c}1000 \mathrm{ppm} \\
\text { MoNaph }\end{array}$ & 60 & 500 & $17.80 \pm 1.76$ & $21.80 \pm 1.95$ & $49.05 \pm 1.02$ & $11.35 \pm 0.50$ & -12.24 \\
\hline
\end{tabular}

Weight of hexahydroanthracene is $1.22 \mathrm{~g}$ which yields $1 \mathrm{wt} \%$ donable hydrogen.

${ }^{b}$ ANT = anthracene; DHA = dihydroanthracene; HHA = hexahydroanthracene; OHA = octahydroanthracene; Naph = naphthenate; HYD = hydrogenation 


\section{PART II}

\section{MILD ACIDIC PRETREATMENT TO ENHANCE LOW SEVERITY LIQUEFACTION PROMOTED BY CYCLIC OLEFINS}

\section{Introduction}

To allow coal liquefaction to be feasible, there has to be an adequate conversion to coal liquids to justify the work needed. Low severity liquefaction is much cheaper than traditional methods at high temperatures and pressures. This is still an expensive process, so conversion needs to be improved. This can be done by introducing better hydrogen donor solvents into the system. Pretreatment of the coal before liquefaction can also provide better results.

The facility of cyclic olefins as hydrogen donors in low severity coal liquefaction has been shown by the work of Bedell and Curtis (1991). At low severity, the cyclic olefins donated their hydrogen more readily than their hydroaromatic analogues. The purpose of this study is not only to affirm these results, but to investigate the possibility that through pretreatment in a mildly acidic solution, as done by Shams et. al. (1991), coal conversion may further increase. The basis for the postulated effect on coal conversion being that the acid destroys ionic bridges and reduces coordination between oxygen containing functional groups. This allows better contact between coal and solvent. More importantly, alkaline and alkaline earth cations which inhibit hydrogen transfer are removed. If this is indeed the case, the work of Miller could be expanded to include more than just the hydrochloric acid in methanol solution used in his study. An acid more suitable to the needs and restrictions of industry could possibly be found that would have the same effect. One such possibility would be an aqueous sulfuric acid pretreatment.

The cyclic olefin being used in this study is $1,4,5,8$-tetrahydronaphthalene, isotetralin (ISO). In order to realize the significance of the ISO as a hydrogen donor in the conversion of 
coal, it is necessary to observe the effectiveness of coal conversion of its hydroaromatic analogue, 1,2,3,4-tetrahydronaphthalene (TET). Wyodak subbituminous coal from the Argonne Premium Sample Bank is the coal being used initially in this study, because the heightened effect pretreatment seems to have on low rank coals. To determine the conversion, a method of separation for the reaction products must be developed. Development of this procedure and determination of the conversion of treated and untreated coal with TET as the hydrogen donor solvent were the emphasis of the work for this quarter.

\section{Experimental}

Each tubular microreactor reactor is loaded with $1 \mathrm{~g}$ of Wyodak subbituminous coal from the Argonne Sample Bank. Pretreated coal is reacted along with untreated coal to make a good comparison. The coal is dried in a vacuum oven at 22 inches mercury vacuum for approximately $12 \mathrm{hr}$. To this is added approximately $1.33 \mathrm{~g}$ hexadecane $(99 \%$ purity from Aldrich) and $0.66 \mathrm{~g}$ TET (99\% purity from Aldrich). This ratio provides about $1 \%$ donable hydrogen. The reactions are all being run at $350^{\circ} \mathrm{C}$ and $500 \mathrm{psi}_{2}$ for $30 \mathrm{~min}$.

Conversion of coal to tetrahydrofuran (THF) soluble products is a method often used to determine the effectiveness of a liquefaction method. This conversion is defined by the expression,

$$
\% \text { conversion }=1-\left(\frac{\mathrm{IOM}_{\text {maf }}}{\mathrm{Coal}_{\text {maf }}}\right)
$$

where, $\quad \mathrm{IOM}=$ insoluble organic matter (not soluble in THF)

$$
\text { maf }=\text { on a moisture and ash free basis. }
$$


In order to be able to solve this equation, a good method must be developed to separate the IOM in the reaction products from the THF solubles. The method used by An-Ping Huang reported in previous quarterly reports involves adding THF to the reaction products and decanting the THF and THF solubles off. This is done by transferring the solution to a Nalgene bottle and centrifuging it. By building on the procedure used for coal pretreatment with the acidic solution, an alternate procedure was developed in which the separation is accomplished using filtration instead of decanting.

The vessels used in the THF extraction; a beaker, a round bottom flask and a piece of filter paper, are weighed prior to the procedure. THF is added to the tubing bomb reactor, stirred, and then transferred to the beaker. The solution is sonicated in the beaker to ensure that all of the THF solubles are dissolved. The solution is then vacuum filtered to separate the IOM from the THF soluble material. IOM both remains in the beaker and is transferred onto the filter paper. The filtrate is then poured into a round bottom flask and placed in a rotavapor. The weights of the residue in the beaker and on the filter paper constitute the IOM. By placing the coal in the vacuum oven after pretreatment, all of the moisture is driven off. This has been verified using the data for the coal provided by Argonne. In order to achieve a moisture and ash free basis, the weight of the coal and IOM must only be reduced according to the amount of ash in the coal. The residue in the flask is also weighed to determine recovery. A detailed, step-by-step procedure is found in the appendix.

It is hoped that this method can provide more reliable separation of the two species. This method avoids the possible loss of product caused by the transfer into and out of the centrifuge bottle. The work done last quarter has yielded a relatively low percent recovery. The recovery achieved with both acid treated and untreated coal remained around $75 \%$. 


\section{Results and Discussion}

Recovery is very important to getting defendable results. While the THF extraction procedure may seem fairly simple, there has been some difficulty achieving good recovery (Figure 1). The acceptable range for recovery should be from 90 to $110 \%$. Each of the separations has yielded a recovery much lower than that. There is material being lost somewhere. A meticulous look at the reaction may provide some idea where the loss is occurring. It is possible that the loss may be due to the gas produced in the reaction, or the rotovapor may be pulling off more than just THF. Before the work may continue the problem must be resolved.

Although the recovery problem exists, pretreatment does seem to influence coal conversion. The untreated coals yielded a higher percentage of IOM than the pretreated coals. There was about a $7 \%$ difference between the pretreated and untreated coals. Unfortunately, without better recovery, these numbers are not completely reliable. It is doubtful that any IOM is being lost, so it is possible that theses results are close to what they should be. Recovery will have to be increased substantially, to give more credibility to the results.

For a large part of the quarter, the gas chromatograph was down, making it impossible to do a detailed analysis of the liquefaction products, but the problem has been resolved. This analysis may provide some answers to the loss of material.

\section{Summary}

Due to the poor recovery, the experimental procedure needs to be reviewed. Because of the frequency of the error, there is a problem in the procedure itself. Until this problem is solved, nothing further can be done. It is encouraging that even with such poor recovery, the reactions yielded conversions which were relatively similar. 
Plans have been made to work through a matrix of differing acids and solutions. If the procedure can be made quick and reliable, the possible parameters are endless. Different acids, solvents and ranks of coal can all be tried. It has already been shown that the pretreatment improves coal conversion, now the system that combines the best conversion with the most feasible acid and solvent must be found.

\section{References}

Bedell, M.W. and Curtis, C.W. "The Chemistry and Reactivity of Cyclic Olefins as Donors in Coal Liquefaction," Energy and Fuels, 5, 469, 1991.

Bedell, M.W. "An Investigation Into Use of Cyclic Olefins as New Hydrogen Donors for Coal Liquefaction and Coprocessing Reactions," 1991.

Curtis, C.W. Quarterly Report "Low Severity Coal Liquefaction Promoted by Cyclic Olefins," October-December 1992.

Shams, K.; Miller, R.L. and R.M. Baldwin "Enhancing Low Severity Coal Liquefaction Reactivity Using Mild Chemical Pretreatment," Fuel, 1015-1023, 1992. 


\section{APPENDIX A \\ Procedure for Solvent Extraction of Coal Liquefaction Products}

1. Weigh two $150-\mathrm{ml}$ beakers, two $250-\mathrm{ml}$ round bottom flasks and two sheets of filter paper (11.0 cm Whatman 5 Qualitative or something of similar size and porosity).

2. Place tubing bombs from parallel reactions in sonicator.

3. Fill the bombs and pings from the lids with HPLC grade tetrahydrofuran from Fisher (THF) or other solvent. Using a spatula, scrape the inside of each of the tubing bombs to remove coal from the sides. Rinse the spatula with THF over the beaker reserved for that bomb. Pour THF from the bombs and transfer THF from the plugs into the beakers. Repeat this step three times.

4. Sonicate the THF solution in each of the the beakers using the Branson Sonic Power Sonifier Cell Disruptor 350 for 30 sec. Rinse the probe with THF over the beaker.

5. Place the filter paper into a large funnel with a fixed perforated filter plate (i.e., $114 \mathrm{~mm}$ Coors porcelain funnel) that has been sealed into a large vacuum flask with a rubber stopper. Place a vacuum hose onto the flask and open the line. Wet the filter paper with THF to seal it to the funnel. Pour the solution out of the beaker slowly onto the filter paper. If the solution is poured too quickly, the vacuum will not be able to draw it through the filter paper quickly enough, and some of the coal will go past the edge of the filter paper and be lost. Coal may be allowed to stay in the beaker as it will be washed with more THF later.

6. Repeat steps 3-5 three times. The bombs will be filled a total of nine times. 
7. After the solutions have been filtered three times, the THF has to be removed from the filtrate solution. This can be done by placing it in a Büchi RE 121 Rotavapor for $30 \mathrm{~min}$ (hexane: $40 \mathrm{~min}, 40^{\circ} \mathrm{C}$ and toluene: $3 \mathrm{hr}, 80^{\circ}$ ).

8. After all has been allowed to dry overnight, the beaker, the paper and the flask should be weighed to get IOM and check recovery. If the weight is not stable, it is not completely dry, and more drying time is needed.

9. If hexane and toluene are to be used to further separate the products, two more round bottom flasks will be required for each bomb, but only one beaker and filter paper should be used. The above procedure should be followed using each solvent: hexane first, followed by toluene, then THF. 


\section{APPENDIX B}

\section{Procedure for Mild Acidic Pretreatment of Coal}

1. Using standard weighing paper, weigh out $5 \mathrm{~g}$ of coal to be pretreated. Place this into a 125-ml Erlenmeyer flask with a stopper. To this add $40 \mathrm{ml}$ of methanol (or other solvent) using a buret or other accurate measuring vessel. Using a syringe, add $0.4 \mathrm{ml}$ of concentrated hydrochloric acid (or other acid) to the coal solution. Be sure to rinse the syringe immediately after use to prevent corrosion.

2. Place stopper on flask, and then place flask onto an orbit shaker with the stopper replaced to prevent evaporation of the solvent. Shake the solution vigorously (approximately $300 \mathrm{rpm}$ ) at room temperature for $3 \mathrm{hr}$.

3. Record the weight of one sheet of filter paper $(11.0 \mathrm{~cm}$ Whatman 5 Qualitative or something of similar size and porosity). Place the filter paper into a large funnel with a fixed perforated filter plate (i.e., $114 \mathrm{~mm}$ Coors porcelain funnel) that has been sealed into a large vacuum flask with a rubber stopper. Place a vacuum hose onto the flask and open the line. Wet the filter paper with methanol to seal it to the funnel. Pour the slurry out of the flask slowly onto the filter paper. If the solution is poured too quickly, the vacuum will not be able to draw it through the filter paper quickly enough and some of the coal will go past the edge of the filter paper and be lost. After all of the original solution has been poured onto the filter paper, use a pipet to wash the coal. The coal should be washed first with $150 \mathrm{ml}$ of methanol (in $25 \mathrm{ml}$ increments) to rinse any remaining acid off of the coal. The first couple of aliquots will need to be poured into the flask to finish rinsing the coal out of the flask. It should then be washed with 150 $\mathrm{ml}$ of distilled water to rinse all of the methanol off of the coal. Again this should 
be done slow enough to allow the vacuum to draw the liquid through the filter so the coal does not run to the edge of the funnel.

4. Once the coal has been washed, the filter may be removed easily from the funnel by placing the vacuum hose onto the air line and opening it slightly to create a minor overpressure in the flask. Remove the filter paper carefully and place it onto a petri dish $(11.0 \mathrm{~cm}$ paper will require a $150 \times 15 \mathrm{dish})$. Place it into a vacuum oven at room temperature until it is used.

5. Untreated coal that it used to compare results should be dried under the same conditions. 


\section{APPENDIX C}

\section{Calculations}

The solvent in these reactions needs to contain $1 \mathrm{wt} \%$ donable hydrogen (DH). Each ISO molecule can yield 4 hydrogen atoms so the following ratio exists:

$$
\frac{\text { M.W. ISO }[132.2]}{\text { M.W. DH[4.0] }}=\frac{\text { ISO charge }}{(\% \text { DH })(\text { Total solvent charge })}
$$

This can easily be solved to find \% donable hydrogen.

To calculate conversion:

$$
\begin{gathered}
\% \text { conversion }=1-\frac{\text { [grams THF insolubles }- \text { grams ash] }}{\text { [grams coal charged -grams } \left.\mathrm{H}_{2} \mathrm{O}_{\text {in coal }}-\text { grams ash }_{\text {in coal }}\right]} \\
\text { grams ash }=0.0631 \text { (Total weight of coal) } \text { [for Wyodak] } \\
\text { grams } \mathrm{H}_{2} \mathrm{O}=0 \quad \text { [for feed coal dried in the vacuum oven] }
\end{gathered}
$$


Figure 1. Conversion of Wyodak Coal Reacted with Isotetralin ${ }^{\mathrm{a}}$

\begin{tabular}{||l|c|c|c|c|c|c|c||}
\hline & \multicolumn{3}{|c|}{ Untreated Coal } & \multicolumn{4}{c|}{$\begin{array}{c}\text { Coal Pretreated with } \\
\text { HCL in CH OH }\end{array}$} \\
\hline Reaction Set & A & B & B & A & A & B & B \\
\hline \% Donable Hydrogen & 1.02 & 1.00 & 1.03 & 1.02 & 1.01 & 1.01 & 1.01 \\
\hline \% Coal Conversion & 15.8 & 17.5 & 17.7 & 22.8 & 21.8 & 25.8 & 26.3 \\
\hline \% Recovery & 74.9 & 74.7 & 79.4 & 77.3 & 78.3 & 70.0 & 75.3 \\
\hline
\end{tabular}

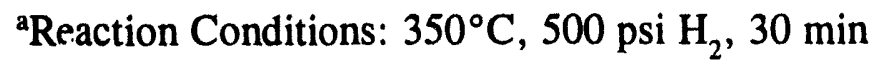



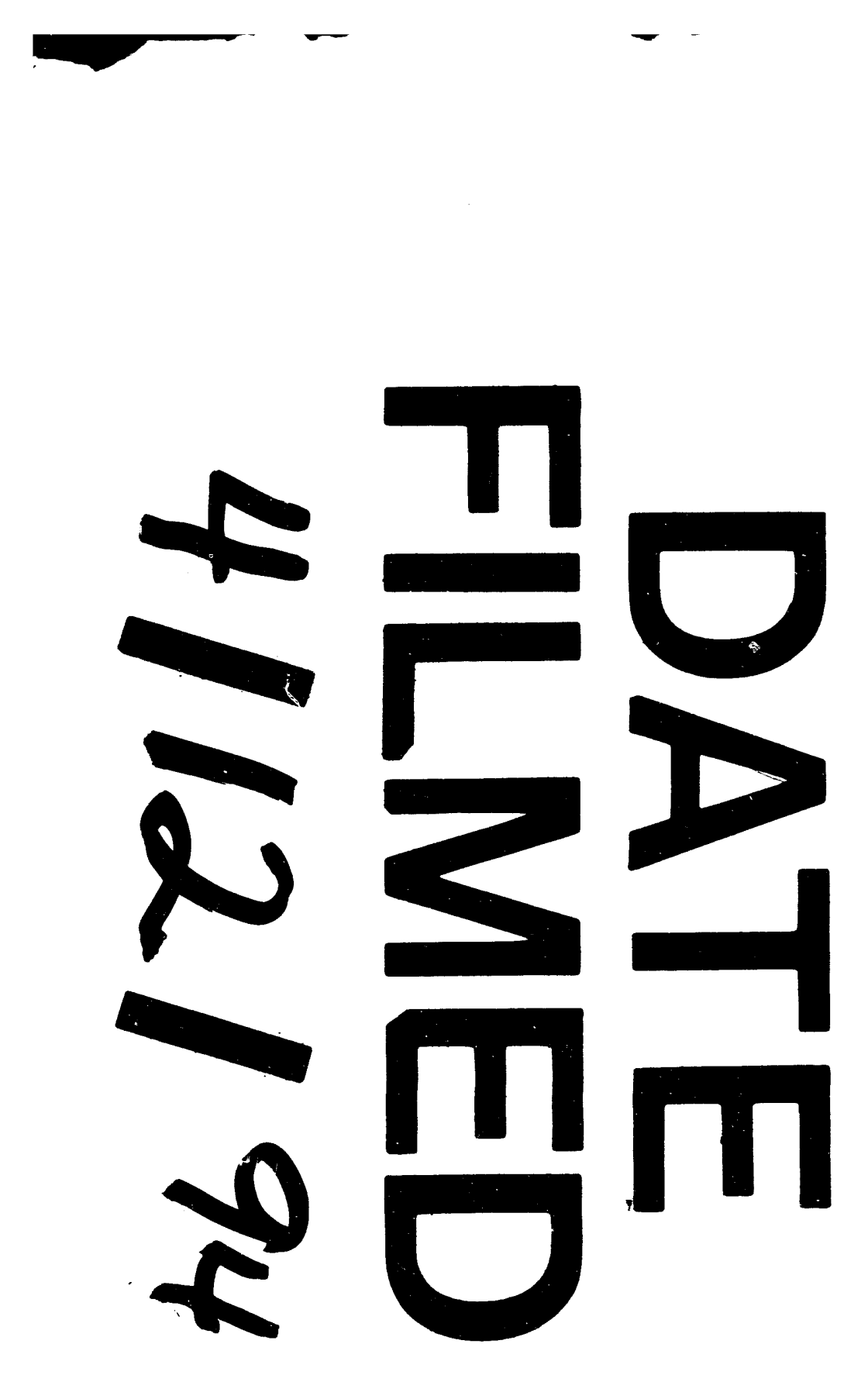
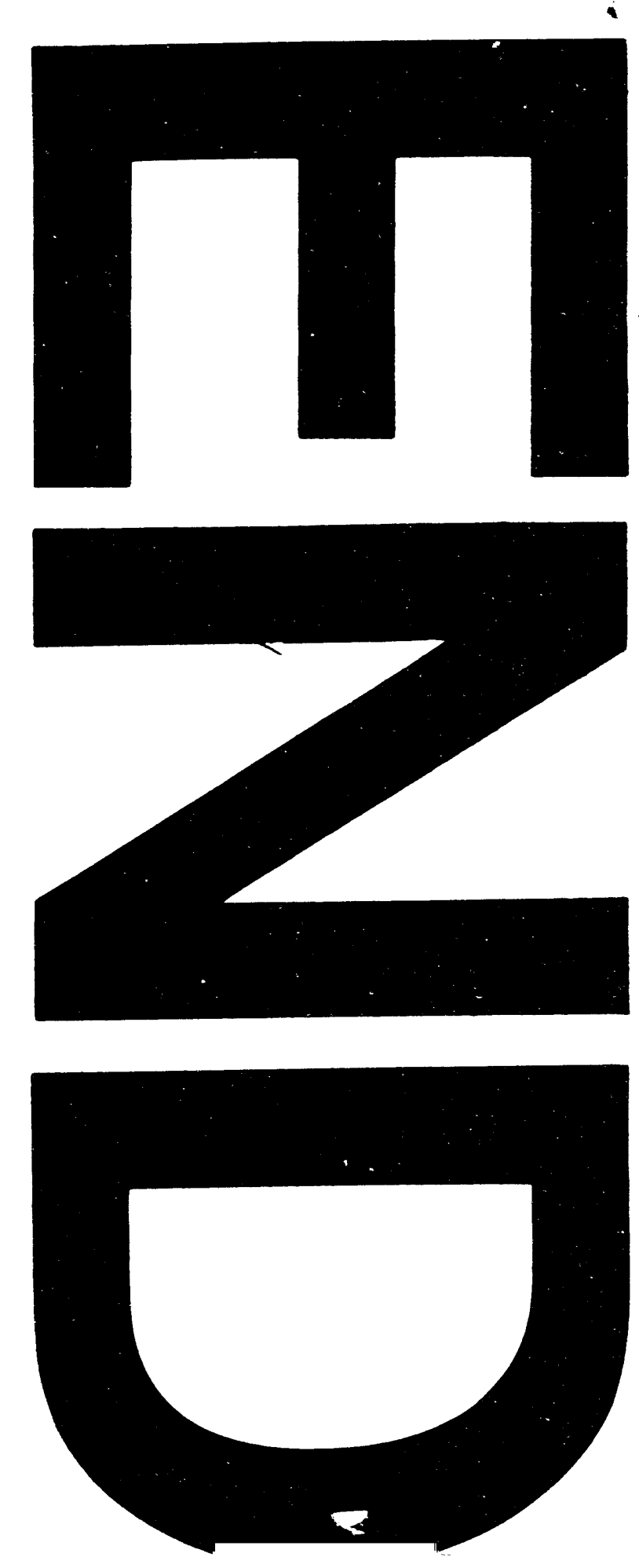
